\title{
Papilomatose oral em cães: revisão da literatura e estudo de doze casos
}

\author{
Papilomatosis in dogs: \\ literature review and study of twelve cases
}

\author{
Marta Catarina Fernandes ${ }^{1 *}$; Márcio Garcia Ribeiro ${ }^{2}$; Fabiana Pólis Fedato \\ Antonio Carlos Paes ${ }^{2}$; Jane Megid ${ }^{2}$
}

\section{Resumo}

Papilomatose canina é uma enfermidade infecto-contagiosa viral caracterizada pela formação de papilomas orais, cutâneos ou oculares, geralmente benignos. O tratamento é indicado quando ocorre persistência dos tumores, lesões múltiplas causando obstrução faringeana, disfagia ou por razões estéticas. Diferentes protocolos de tratamento são descritos incluindo excisão cirúrgica, criocirurgia, eletrocirurgia, vacinas autógenas ou recombinantes, drogas imunomoduladoras, quimioterapia sistêmica ou intralesional. Foram revisados os principais aspectos clínico-epidemiológicos da papilomatose oral canina. Nos 12 animais estudados foram observados papilomas predominantemente em região de língua, gengiva e palato, com até 12 meses de idade e infecção combinada com erliquiose. $\mathrm{O}$ tratamento com Propionibacterium acnes e/ou vacina autócne surtiu efeito em oito animais $(66,7 \%)$.

Palavras-chave: Cão, papilomatose, Papillomavirus, clínica, epidemiologia, terapia

\begin{abstract}
Canine papillomatosis is an infectious viral disease characterized by oral, cutaneous or ocular papillomas, usually benign. The treatment is indicated in animals, with multiple tumors that produce pharyngeal obstruction, and problems of eating or for aesthetic reasons. Different treatment protocols have been proposed, including surgical excision, cryosurgery, electro surgery, autogenous or recombinant vaccines, imunomodulators drugs, systemic and intralesional chemotherapy. In this study were reviewed the more important aspects of canine oral papillomatosis. In the 12 studied animals, the papillomas were observed predominantly in mouth, gum and palate regions, in puppies until 12 months, presenting combined infection with ehrlichiosis. The treatment using Propionibacterium acnes and/or autogenous vaccine showed efficacy in eight dogs $(66.7 \%)$.
\end{abstract}

Key words: Dog, papilomatosis, Papillomavirus, clinic, epidemiology, therapy

\footnotetext{
1 Residente em Enfermidades Infecciosas dos Animais do Departamento de Higiene Veterinária e Saúde Pública - FMVZ/UNESP - Botucatu, SP, Brasil. E-mail: martafernandesunesp@hotmail.com

2 Professores da Disciplina de Enfermidades Infecciosas dos Animais do Departamento de Higiene Veterinária e Saúde Pública FMVZ/UNESP - Botucatu, SP, Brasil.

3 Médica Veterinária Autônoma.

* Autor para correspondência
} 


\section{Revisão de Literatura}

A papilomatose canina é causada por vírus do gênero Papillomavirus, família Papovaviridae. Possuem simetria icosaédrica, constituídos por DNA de fita dupla. São pequenos (55nm) e desprovidos de envelope. A ausência de envelope confere maior resistência do vírus no ambiente. Apresentam termo-estabilidade e são resistentes ao pH ácido, ao éter e aos solventes lipídicos (WALL; CALVERT, 2006). Mantém-se viável por 63 dias entre $4-8^{\circ} \mathrm{C}$ ou 6 horas a $37^{\circ} \mathrm{C}$, porém temperaturas entre 45 e $80^{\circ} \mathrm{C}$ por 60 minutos inativam o vírus (NICHOLLS; STANLEY, 1999). Apresenta alta especificidade por espécies animais e tecidos ou órgãos, podendo ocorrer lesões de forma isolada ou múltipla, localizadas principalmente na região oral, genital, cutânea e ocular (BRANDSMA, 1994).

Wall e Calvert (2006) referem que não há predileção por sexo, raça dos animais e sazonalidade na ocorrência da doença. A transmissão ocorre por contato direto ou indireto com secreções ou sangue provenientes dos papilomas, embora lesões na superfície epitelial favoreçam a infecção. Papillomavirus possui mecanismos de evasão da resposta imune do hospedeiro, que permitem a sua replicação e manifestação patogênica. Acomete predominantemente cães jovens ou adultos imunossuprimidos (NICHOLLS; STANLEY, 1999). A maior susceptibilidade de cães jovens à infecção sugere que cães adultos adquiram imunidade devido ao contato prévio com o vírus (NICHOLLS; STANLEY, 2000). A maioria das infecções regride espontaneamente entre quatro a oito semana pósinfecção. Entretanto, ocasionalmente, os papilomas podem persistir ou recidivar, especialmente em cães imunossuprimidos. A infecção de cães com doenças imunossupressivas ou debilitantes (erliquiose, cinomose, parvovirose) favorece a replicação e a manifestação clínica do Papillomavirus. Wall e Calvert (2006) descreveram que após o tratamento de cães com erliquiose monocítica foi observada a remissão dos papilomas.
Geralmente cães que sofreram infecção e regressão total dos papilomas se tornam resistentes a reinfecção. No entanto, podem ocorrer casos de recidiva dos papilomas devido ao não estabelecimento da resposta imune adequada ou por deficiências da imunidade do animal susceptível (WALL; CALVERT, 2006).

As lesões tumorais benignas podem progredir para forma maligna, como o carcinoma de células escamosas, considerada afecção clínica rara (TIEFKE; LOHR; SHIRASAWA, 1998).

A morbidade é alta em canís, hospitais veterinários, clínicas ou ambientes similares com alto fluxo e rotatividade de animais, podendo acometer ninhadas inteiras. Todavia, a mortalidade é baixa, exceto nos casos com complicações secundárias que comprometam o estado geral do animal (CORRÊA; CORRÊA, 1992).

$\mathrm{O}$ vírus infecta as células basais do estrato germinativo, em divisão ativa, resultando em acantose e hiperqueratose. Sugere-se que estas células possam manter o vírus em estado latente. Papillomavirus induz à hiperplasia, levando ao aumento da divisão das células basais e retardo na maturação das células da camada espinhosa e granulosa. Nas células do estrato espinhoso, o gene viral expressa as proteínas do capsídio do agente. No estrato granuloso, a quantidade de vírus é mais pronunciada. As partículas virais são liberadas com a esfoliação das células do estrato córneo da pele e das células não queratinizadas da superfície da mucosa (CHOW; BROKER, 1997).

As lesões na cavidade oral são a principal forma de apresentação clínica da papilomatose em cães. A papilomatose oral ocorre preferencialmente nos lábios, língua, palato, mucosa da faringe e esôfago. Papilomas oculares ocorrem em conjuntiva, córnea e margem palpebral. As lesões se desenvolvem nos cães predominantemente entre um a cinco meses, regredindo na maioria dos casos quatro a oito semanas após o início das lesões, podendo, ocasionalmente, tenderem a cronicidade (CHAMBERS; EVANS, 1959; CALVERT, 1990). 
Raramente os papilomas causam problemas graves. Entretanto, dependendo de sua localização, podem comprometer o estado geral do animal devido à obstrução faringeana e disfagia (BREDAL et al., 1996). Ptialismo, halitose, hemorragia, infecções bacterianas secundárias, acompanhada por secreção purulenta na região dos papilomas, são complicações clínicas observadas na doença em cães (CALVERT, 1998). Os papilomas geralmente se apresentam com aspecto de verrugas e de consistência dura. A coloração varia da tonalidade branco acinzentada a negra, com superfícies ásperas e friáveis que se destacam facilmente gerando hemorragias. As lesões variam de pequenos nódulos circunscritos - menores que $0,5 \mathrm{~cm}$ de diâmetro - até grandes massas desuniformes, popularmente denominadas "couve-flor" ou "verrugas".

Nicholls et al. (2001) salientaram evidências morfológicas da ação dos linfócitos na regressão do papiloma. $\mathrm{O}$ afluxo de linfócitos começa exatamente anterior à regressão, atingindo o pico durante a cicatrização da lesão, e retornando aos níveis de préinfecção após a resolução do processo. Células CD4+ são mais abundantes que as células CD8+. Apesar de neutralizar a infecção, as imunoglobulinas (Ig) não levam à regressão dos papilomas, mas protegem cães susceptíveis quando desafiados (SUZICH et al., 1995; GHIM et al., 1997a, 1997b). A deficiência de imunoglobulinas (Ig) das classes IgA ou IgM e a hipogamaglobulinemia são relatadas em cães severamente afetados (MILL; CAMPBELL, 1992; SUNDBERG et al., 1994; BREDAL et al., 1996).

A imunossupressão induzida pela terapia com corticosteróide ou quimioterapia é relacionada à ocorrência de papilomas orais e cutâneos em cães. Após três semanas do término da terapia pode ser observada a regressão das lesões (SUNDBERG etal., 1994; LE NET et al., 1997; LUCROY et al., 1998). O diagnóstico da papilomatose canina rotineiramente é baseado nos achados clínicos. Entretanto, outros métodos estão disponíveis para o diagnóstico. Dentre estes merecem destaque a detecção viral, a histopatologia, a imunohistoquímica, a microscopia eletrônica ou técnicas moleculares que visam à identificação específica do DNA viral (BREDAL et al., 1996), embora estes métodos estejam restritos a estudos experimentais, em virtude do alto custo ou baixa disponibilidade de laboratórios capacitados para a realização destas técnicas.

$\mathrm{Na}$ histopatologia é evidenciada hiperplasia do epitélio pavimentoso estratificado, podendo até se estender para a derme. O estrato espinhoso é a camada mais espessa da epiderme, onde geralmente ocorre perda das pontes intercelulares. A hiperplasia é sustentada por uma haste fibrovascular (SHIMADA et al., 1993; BREDAL et al., 1996). A imunohistoquímica é utilizada para detecção de antígenos estruturais do Papillomavirus utilizando anticorpos monoclonais e policlonais (SUNDBERG et al., 1994).

A microscopia eletrônica permite a visualiza de estrutura hexagonal densa do vírus no núcleo das células das camadas do estrato granuloso e estrato córneo (SHIMADA et al., 1993), permitindo o diagnóstico direto do vírus. Nos últimos anos, temse utilizado técnicas moleculares no diagnóstico, visando a detecção de material genético e seqüenciamento viral mediante a reação em cadeia de polimerase (PCR) (BREDAL et al., 1996).

A terapia da papilomatose é assunto controverso entre os pesquisadores. Apesar da diversidade de fármacos e métodos descritos, não existe até $o$ momento protocolo terapêutico altamente eficiente e que possa ser indicado com reprodutibilidade de resultados. Adicionalmente, o comportamento autolimitante da doença resulta em que grande parte dos animais não sejam tratados (TIZARD, 2000), ou que tenham a cura associada a métodos e protocolos empíricos de terapia.

Nos quadros clínicos complicados, como ulceração dos tumores e obstrução faringeal, ou por motivos estéticos, estão disponíveis vários protocolos terapêuticos, que incluem ressecção cirúrgica, fármacos anti-virais, vacinas autócnes ou fármacos imunomoduladores (TIZARD, 2000; NICHOLLS; STANLEY, 2000). 
A excisão cirúrgica ou a criocirurgia são eficientes no tratamento de papilomas cutâneos, orais ou de conjuntiva. Entretanto, não são indicadas no papiloma de córnea. À semelhança de outros protocolos terapêuticos empregados na papilomatose canina, em virtude da regressão espontânea, é difícil comprovar a relação entre intervenção cirúrgica e a resolução clínica (CALVERT, 1998).

Quimioterapia sistêmica ou local utilizando agentes como a vincristina, ciclofosfamida ou doxorrubicina mostraram resultados controversos ou pouco eficientes na maior parte dos ensaios terapêuticos em cães (CALVERT, 1998).

Benites e Melville (2003) relataram a utilização de medicamentos homeopáticos no tratamento da papilomatose canina. Um animal foi tratado com Thuja occ. $30 \mathrm{CH}$, administrada duas vezes por dia, durante três dias. Após 15 dias de tratamento o animal apresentou significativa redução na quantidade de papilomas. Posteriormente, foi submetido à administração de Nitric acid $30 \mathrm{CH}$, duas vezes por dia, durante três dias, que resultou em cura completa em uma semana.

Navacinaçãoautógena eheterógena sãoutilizados extratos dos papilomas inativados com solução de formalina. Esta modalidade de tratamento é descrita há muitos anos com finalidade terapêutica, visto que tem sido indicada no tratamento da papilomatose em animais de produção e de companhia, em detrimento da profilaxia. Ghim et al. (1995) relataram que o uso de vacina contendo a partícula viral L1 protegeu cães contra a doença. Nicholls e Stanley (2000) observaram que a vacinação utilizando o fragmento de DNA que codifica a proteína L1, estimulou a produção de imunidade celular e humoral, sendo efetiva na prevenção da infecção em cães desafiados, recomendando a vacina na profilaxia da doença. Entretanto, Meunier (1990) alertou para o desenvolvimento de carcinoma de células escamosas ou outros tipos de neoplasias no local de aplicação das vacinas.
Propionibacterium acnes (P. acnes), anteriormente denominado Corynebacterium parvum, caracterizam-se como bactérias Grampositivas, pleomórficas, que têm sido utilizadas recentemente como imunoestimulantes inespecíficos em medicina humana, notadamente na terapia antitumoral e antibacteriana, pelas vias tópica e/ou parenteral. A fagocitose de $P$. acnes por macrófagos induz a síntese de citocinas, estimulação das células natural killer (NK) e fator de necrose tumoral. As células NK, juntamente com as células T citotóxicas, promovem incremento na atividade tumoricida, que justificariam a resolução de processos neoplásicos, incluindo a papilomatose canina. P. acnes foi utilizado com sucesso como agente imunomodulador no tratamento de 16 cães de várias idades, de diferentes raças e sexos. O tratamento inicial constituiu de administração semanal de 2,0 mg de $P$. acnes, via intramuscular profunda, até a regressão das lesões. A aplicação semanal do $P$. acnes nos animais jovens resultou em regressão rápida das lesões a partir da segunda aplicação, e resolução completa após a quinta aplicação do imunomodulador. Em virtude da regressão mais acentuada dos papilomas nos animais jovens, o intervalo de aplicação nos animais adultos foi reduzido para três dias. Neste protocolo, após a terceira aplicação do imunomodulador foi constatada coloração enegrecida e ressecamento das lesões, com tendência à cicatrização no máximo na sexta aplicação (MEGID et al., 2001).

Medidas simples de controle da doença incluem o isolamento dos animais acometidos até a completa resolução dos papilomas, e evitar adquirir animais com lesões ou provenientes de criatórios com histórico da doença (CORRÊA; CORRÊA, 1992). Imunizações subseqüentes com vacina autócne ou recombinantes podem ser utilizadas para a prevenção da papilomatose. Entretanto, até o momento, nenhuma vacina está disponível comercialmente (WALL; CALVERT, 2006). 


\section{Relato dos Casos}

Foram estudados os aspectos clínicoepidemiológicos e terapêuticos de 12 casos de papilomatose oral canina, atendidos no serviço ambulatorial de Enfermidades Infecciosas dos Animais da Faculdade de Medicina Veterinária e Zootecnia - UNESP/ Botucatu, SP, entre 2001 a 2006.

$\mathrm{Na}$ anamnese os proprietários dos animais relataram histórico de formação de lesões (papilomas) na cavidade oral, de odor fétido, inapetência, com evolução de um a três meses. Dos 12 animais estudados, dez machos e duas fêmeas, sete eram sem raça definida, e seis possuíam até 12 meses de idade.

O exame da cavidade bucal revelou halitose e presença de papilomas preferencialmente em língua, gengiva e palato. Os papilomas eram de consistência dura, com aspecto de verrugas, desuniformes, de coloração branco-amarelada a enegrecida, variando de pequenos nódulos a grandes massas (Fig. 1). Em alguns casos observou-se a presença de secreção purulenta ao redor dos papilomas, decorrente de contaminação bacteriana secundária.

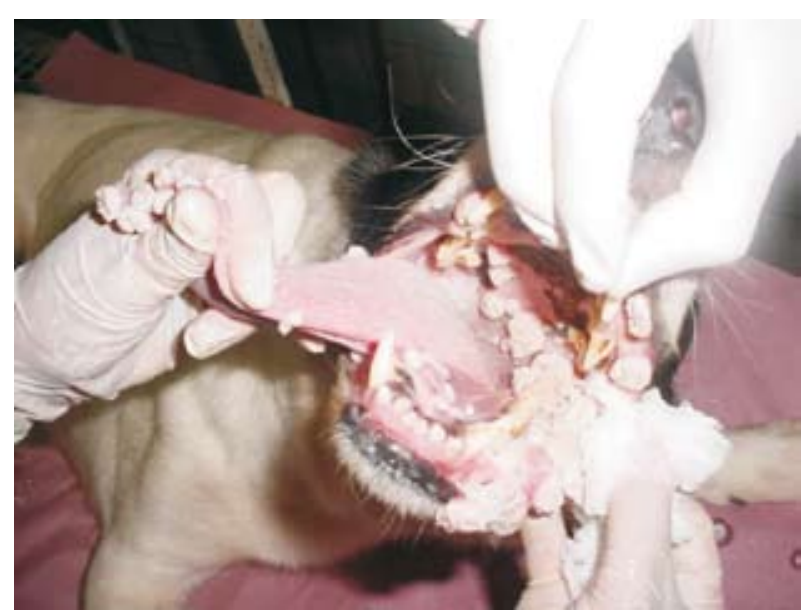

Figura 1. Múltiplas lesões na cavidade bucal na papilomatose em cão de 10 anos de idade. Botucatu, 2006.
Em seis animais foi diagnosticada infecção combinada com erliquiose. O diagnóstico de erliquiose foi fundamentado nos achados clínicoepidemiológicos, aliado a exames subsidiários, incluindo a presença de pancitopenia (anemia, leucopenia e trombocitopenia) e/ou a visualização de mórulas do parasita no hemograma completo.

Os parâmetros hematológicos revelaram pancitopenia em um animal portador da erliquiose, anemia intensa em dois animais e anemia discreta em sete animais. Leucocitose discreta com neutrofilia foi observada em três animais, enquanto outros três animais mostraram leucopenia e linfopenia. Monocitose foi encontrada em quatro animais. Trombocitopenia foi observada em todos os animais com erliquiose (Tab. 2).

A tabela 1 apresenta os principais achados clínicoepidemiológicos e procedimentos terapêuticos nos 12 casos de papilomatose oral em cães.

A terapia foi instituída em nove animais utilizando $P$. acnes (Infervac ${ }^{\circledR}$ ) na dose de $1 \mathrm{~mL}$ $\left(1 \times 10^{9} \mathrm{UFC}\right)$, via intramuscular, em protocolos que variaram de dose única a aplicações a cada 3 a 7 dias (4 a 8 aplicações), dependendo da gravidade dos sintomas. Nestes casos, quanto maior o número e gravidade das lesões, menor o intervalo entre as aplicações (Tab. 1) .

Dois animais receberam somente vacina autócne, produzida assepticamente utilizando fragmentos colhidos dos animais acometidos, inativada por solução de formalina. A vacina autócne foi utilizada na dose de $3 \mathrm{~mL}$, via subcutânea, a cada 15 dias. $\mathrm{O}$ animal restante recebeu duas doses de $P$. acnes, com intervalo de 48 horas, seguido da aplicação de vacina autócne a cada 15 dias, perfazendo um total de três doses.
${ }^{4}$ Infervac ${ }^{\circledR}$ - Laboratórios Calier S.A., Barcelona, Espanha. 
Com intuito de evitar contaminações bacterianas na cavidade oral, seis animais foram tratados com penicilina benzatina $(20.000 \mathrm{UI} / \mathrm{Kg}), \mathrm{IM}$, a cada cinco dias, com 3 a 4 repetições. Os animais com erliquiose foram tratados com doxiciclina $(15 \mathrm{mg} /$ $\mathrm{Kg}$ ), via oral, a cada 24 horas, por 21 dias.

Tabela 1. Dados clínico-epidemiológicos e procedimentos terapêuticos em doze cães com papilomatose oral canina. Botucatu, 2006.

\begin{tabular}{|c|c|c|c|c|c|c|}
\hline Animal no & Raça & Sexo & Idade & $\begin{array}{c}\text { Doença } \\
\text { concomitante }\end{array}$ & Tratamento & Evolução \\
\hline \multicolumn{7}{|c|}{ P. acnes (Infervac $\left.{ }^{\circledR}\right)$} \\
\hline & \multicolumn{6}{|c|}{ Animais de 0 a 12 meses } \\
\hline 1 & Pastor alemão & $\mathrm{F}$ & 5 meses & - & dose única & regressão \\
\hline 2 & SRD & M & 6 meses & erliquiose & $\begin{array}{l}\text { 7/7 dias } \\
\text { (3 aplicações) }\end{array}$ & regressão \\
\hline 3 & Pitbull & M & 6 meses & erliquiose & dose única & regressão \\
\hline 4 & Teckel & M & 9 meses & erliquiose & $\begin{array}{l}\text { 7/7 dias } \\
\text { (3 aplicações) }\end{array}$ & regressão \\
\hline \multirow[t]{2}{*}{5} & SRD & M & 11 meses & erliquiose & $\begin{array}{l}\text { 7/7 dias } \\
\text { (2 aplicações) }\end{array}$ & óbito ${ }^{1}$ \\
\hline & \multicolumn{6}{|c|}{ Animais $\geq 13$ meses } \\
\hline 6 & Poodle & M & 6 anos & erliquiose & $\begin{array}{l}\text { 7/7 dias } \\
\text { (2 aplicações) }\end{array}$ & regressão \\
\hline 7 & SRD & M & 8 anos & - & $\begin{array}{l}\text { 7/7 dias } \\
\text { (3 aplicações) }\end{array}$ & óbito ${ }^{3}$ \\
\hline 8 & SRD & M & 10 anos & - & $\begin{array}{l}3 / 3 \text { dias } \\
\text { (8 aplicações) }\end{array}$ & óbito ${ }^{2}$ \\
\hline 9 & SRD & $\mathrm{F}$ & Adulto & erliquiose & $\begin{array}{l}\text { 7/7 dias } \\
\text { (2 aplicações) }\end{array}$ & regressão \\
\hline \multicolumn{7}{|c|}{ Vacina Autócne } \\
\hline 10 & SRD & $\mathrm{M}$ & 3 anos & - & 2 doses $/ 21$ dias & regressão \\
\hline 11 & SRD & M & 7 anos & - & 2 doses / 21 dias & desconhecida \\
\hline \multicolumn{7}{|c|}{ P. acnes $*+$ vacina autócne $* *$} \\
\hline 12 & Pitbull & M & 8 meses & - & $\begin{array}{l}*-2 \text { aplicações/ } \\
\text { a cada } 48 \mathrm{~h} \\
* *-15 / 15 \text { dias/ } \\
3 \text { doses }\end{array}$ & regressão \\
\hline
\end{tabular}

1-óbito por erliquiose

2-óbito por obstrução faringeana

3-eutanasiado por complicações secundárias da papilomatose

P. acnes $=$ Propionibacterium acnes: Infervac ${ }^{\circledR}-$ Laboratórios Calier S.A., Barcelona, Espanha.

$\mathrm{M}=$ macho; $\mathrm{F}=$ fêmea

$\mathrm{SRD}=$ sem raça definida 
Tabela 2. Achados hematológicos em doze cães com papilomatose oral. Botucatu, 2006.

\begin{tabular}{|c|c|c|c|c|c|c|c|}
\hline \multirow[b]{2}{*}{ Animal no } & \multicolumn{2}{|c|}{ Hematimetria } & \multicolumn{4}{|c|}{ Leucometria } & \multirow[t]{2}{*}{ Plaquetas } \\
\hline & $\begin{array}{l}\text { Hemácias } \\
\left(\mathrm{x} 10^{6} / \mu \mathrm{L}\right)\end{array}$ & $\begin{array}{c}\text { Volume } \\
\text { globular } \\
(\%)\end{array}$ & $\begin{array}{c}\text { Leucócitos } \\
(\mathrm{cel} / \mu \mathrm{L})\end{array}$ & $\begin{array}{c}\text { Neutrófilos } \\
(\text { cel/ } \mu \mathrm{L})\end{array}$ & $\begin{array}{c}\text { Linfócitos } \\
(\mathrm{cel} / \mu \mathrm{L})\end{array}$ & $\begin{array}{l}\text { Monócitos } \\
(\text { cel/ } \mu \mathrm{L})\end{array}$ & \\
\hline 1 & 2,4 & 16 & 9.400 & 7.050 & 846 & 1.316 & 150.000 \\
\hline 2 & 1,8 & 11 & 14.257 & 9.409 & 1.710 & 2.708 & 2.525 \\
\hline 3 & 4,0 & 30 & 8.400 & 8.064 & 84 & 252 & 5.050 \\
\hline 4 & 5,1 & 34 & 6.800 & 5.032 & 1.088 & 68 & 80.000 \\
\hline 5 & 2,2 & 17 & 2.058 & 1.852 & 205 & 0 & 15.150 \\
\hline 6 & 2,3 & 16 & 12.900 & 8.256 & 4.128 & 258 & 42.925 \\
\hline 7 & 5,7 & 38 & 19.500 & 16.965 & 1.950 & 1.365 & 280.000 \\
\hline 8 & 4,7 & 32 & 21.000 & 19.110 & 1.680 & 2.100 & 240.000 \\
\hline 9 & 4,3 & 30 & 7.128 & 5.274 & 926 & 784 & 5.050 \\
\hline 10 & 4,4 & 32 & 18.900 & 10.584 & 3.213 & 2.457 & 210.000 \\
\hline 11 & NR & NR & NR & NR & NR & NR & NR \\
\hline 12 & 4,1 & 30 & 11.800 & 6.726 & 4.248 & 590 & 300.000 \\
\hline \multicolumn{8}{|c|}{$\begin{array}{l}\text { Parâmetros de } \\
\text { normalidade* }\end{array}$} \\
\hline Mínimo & 5,5 & 37 & 6.000 & 3.000 & 1.000 & 150 & 200.000 \\
\hline Máximo & 8,5 & 55 & 17.000 & 11.500 & 4.800 & 1.350 & 500.000 \\
\hline
\end{tabular}

* Feldman, Zinkl, e Jain (2000).

$\mathrm{NR}=$ não realizado

$\mathrm{Cel} / \mu \mathrm{L}=$ células $/$ microlitro

$\%=$ porcentagem

Foi observada regressão dos papilomas em oito dos animais tratados. Três animais vieram a óbito (Tab. 1), dos quais dois pelo comprometimento do estado geral - causado pela proliferação intensa dos papilomas na cavidade oral-, notadamente pela dificuldade de alimentação.

\section{Discussão e Conclusões}

Dentre os animais estudados, seis apresentaram à admissão idade inferior a um ano e/ou co-infecção com doença imunossupressora (erliquiose). Estes achados também foram assinalados em estudos similares que apontaram a papilomatose acometendo predominantemente cães com algum grau de imunossupressão - decorrente de doenças infecciosas, - ou animais jovens, com menos de um ano de idade -, cujo sistema imune não está completamente maduro, reforçando o comportamento oportunista do vírus (NICHOLLS et al., 1999; WALL; CALVERT, 2006).
Não há referência à predisposição de raça e sexo dos animais, assim como influência da sazonalidade na ocorrência da papilomatose. Contrariamente, nos doze casos relatados houve predominância de cães sem raça definida, do sexo masculino, com histórico de acesso à rua. De maneira similar ao presente estudo, Wall e Calvert (2006) apontaram que o livre acesso dos animais à rua e o contato com outros cães são fatores que poderiam favorecer o contágio na papilomatose canina.

A papilomatose é considerada doença de baixa freqüência em cães, manifestada pela presença de lesões isoladas ou múltiplas, na cavidade oral, tecido subcutâneo ou região ocular. Nos casos relatados foram observadas lesões múltiplas, exclusivamente na região oral (língua, gengiva e palato), em consonância com outros autores que também referiram a ocorrência de papilomas na cavidade oral como a principal forma de apresentação clínica da papilomatose em cães (CALVERT, 1990, 1998; CORRÊA; CORRÊA, 1992). 
A predominância das lesões na cavidade oral sugere que a ingestão de água e alimentos contaminados, a lambedura de secreções contendo partículas virais, traumatismos e/ou pequenas soluções de continuidade na cavidade oral, representariam as principais vias de transmissão da doença nos cães.

A presença de pancitopenia nos animais com erliquiose (Tab. 2) está de acordo com outros estudos, que apontaram este achado hematológico freqüentemente em cães na fase crônica da doença (WALL; CALVERT, 2006), dificultando a avaliação das alterações hematológicas que poderiam ser creditadas ao Papillomavirus neste grupo de animais.

Via de regra, as infecções a vírus induzem a leucopenia por neutropenia e/ou linfopenia em cães (FELDMAN; ZINKL; JAIN, 2000). Entretanto, este achado hematológico não foi observado nos animais estudados (Tab. 2), reforçando que não existe padrão dos achados do leucograma na papilomatose oral em cães, que pudessem nortear o diagnóstico da doença unicamente por este exame clínico-laboratorial.

Megid et al. (2001) utilizaram P. acnes no tratamento da papilomatose em 16 cães no Brasil, e obtiveram resolução clínica das lesões em todos os animais. No presente estudo, também foi observada boa eficácia do $P$. acnes no tratamento da papilomatose oral em cães, visto que dentre nove animais tratados com este imunomodulador, foi obtida cura das lesões em seis animais (Tab. 1), reforçando o uso de $P$. acnes como alternativa no tratamento da papilomatose canina.

A ocorrência de regressão espontânea da papilomatose em cães, quatro a oito semanas após a infecção (WALL; CALVERT, 2006), dificulta a avaliação da eficácia dos diferentes protocolos terapêuticos. Entretanto, a resolução clínica das lesões nos animais estudados após a aplicação de $P$. acnes, reforça a sua indicação como opção na terapia da papilomatose canina, em virtude de suas propriedades imunomoduladoras, decorrente provavelmente do aumento de produção de citocinas, da estimulação das células natural killer (NK) e do fator de necrose tumoral, que resultam em efeito tumoricida.

Em dois animais foram utilizados exclusivamente a vacina autócne e, em um animal, a associação da autovacina com $P$. acnes (Tabela 1). A avaliação deste grupo de animais tratados com vacina autócne fica limitada face ao restrito número de cães e pela associação em um dos animais de dois protocolos terapêuticos.

Apesardapapilomatoseprovocarbaixaletalidade, determinadas complicações podem comprometer o estado geral do animal (BREDAL et al., 1996). Dos 12 animais estudados, dois apresentaram sérias complicações do estado geral, notadamente pela dificuldade de deglutição dos alimentos, levando a deterioração do quadro e morte. A evolução da doença nestes animais mostra a importância do diagnóstico precoce e rápida instituição da terapia, com vistas a melhorar o prognóstico para cães com papilomatose.

O presente estudo reafirma a importância da papilomatose oral como doença oportunista em animais acometidos por doenças imunossupressivas - como a erliquiose - ou em cães jovens, assim como a boa eficiência do $P$. acnes como fármaco imunoestimulante no tratamento da doença em cães.

\section{Referências}

BENITES, N. R.; MELVILLE, P. A. Tratamento homeopático de papilomatose canina. Clínica Veterinária, São Paulo, v. 8, n. 44, p. 19-20, 2003.

BRANDSMA, J. L. Animal models of humanpapillomavirus associated oncogenesis. Intervirology, Basel, v. 37, n. 3-4, p. 189-200, 1994.

BREDAL, W. P.; THORESEN, S. I.; RIMSTAD, E.; ALEKSANDERSEN, M.; NAFSTAD, P. H. J. Diagnosis and clinical course of canine oral papillomavirus infection. Journal of Small Animal Practice, Oxford, v. 37, n. 3, p. 138-142, 1996. 
CALVERT, C. A. Canine viral papilomatosis. In: GREENE, C. E. Infectious diseases of the dog and cat. 2.ed. Philadelphia: W.B. Saunders, 1998. p. 51-55.

.Environmentalsurvivalofcertainmicroorganisms and some effective bactericidal agents. In: GREENE, C. E. Infectious diseases of the dog and cat. Philadelphia: W.B. Saunders, 1990. Apendix, 9.

CHAMBERS, V. C.; EVANS, C. A. Canine oral papillomatosis. Virus assay and observations on the various stages of the experimental infection. Cancer Research, Baltimore, v. 19, n. 11, p. 1188-1195, 1959.

CHOW, L. T.; BROKER, T. R. In vitro experimental systems for HPV: epithelial raft cultures for investigations of viral reproduction and pathogenesis and for genetic analyses of viral proteins and regulatory sequences. Clinics in Dermatology, Philadelphia, v. 15, n. 2, p. $217-$ 227, 1997.

CORRÊA, W. M.; CORRÊA, C. N. M. Enfermidades infecciosas dos animais domésticos. 2.ed. Rio de Janeiro: Medsi, 1992. p. 709-713.

FELDMAN, B. F.; ZINKL, J. G.; JAIN, N. C. Schalm's veterinary hematology. 5.ed. Philadelphia: Williams \& Wilkins, 2000.

GHIM, S. J.; NEWSOME, J.; BELL, J.; SUZICH, J. A.; SUNDBERG, J. P.; SCHLEGEL, R.; JENSON, A. B. Spontaneously regressing oral papillomas induce systemic antibodies that neutralise canine oral papillomavirus. In: INTERNATIONAL PAPILLOMAVIRUS CONFERENCE, 16., Italy. Anais... Italy: University of Viena, 1997a. p. 322.

GHIM, S. J.; SUN, W. H.; HAJO, D.; NEWSOME, J. T. P.; SUNDBERG, J. P.; SCHLEGEL, R.; JENSON, A. B. Recobinant virus-like particles of equine papillomavirus type-1 and its antigenicity. In: INTERNATIONAL PAPILLOMAVIRUS CONFERENCE, 16., Italy. 1997. Anais... Italy: University of Siena, Italy, 1997b. p. 250.

GHIM, S. J.; NEWSOME, J.; JENSON, A. B.; SCHLEGEL, R.; SUZICHJ.; TAMURA, J.; WHITE, W.; HILL, W.; WARRENER, P.; BELL, J. A.;SUNDBERG, J. Formalin-inactivated oral papilloma extracts and recombinant $\mathrm{L} 1$ vaccines protect completely against mucosal papillomavirus infection. A canine model. Vaccines, New York, v. 95, n. 25, p. 375-379, 1995.

LE NET, J.; ORTH, G.; SUNBERG, J. P.; CASSONNET, P.; POISSON, L.; MASSON, M.; GEORGE, C.; LONGEART, L. Multiple pigmented cutaneous papules associated with a novel canine papillomavirus in an immunosupressed dog. Veterinary Pathology, Washington, v. 34, n. 1, p. 8-14, 1997.
LUCROY, M. D.; HILL, F. I.; MOORE, P. F.; MADEWELL, B. R. Cutaneous papillomatosis in a dog with malignantlymphoma following longterm chemoterapy. Journal Veterinary Diagnostic Investigation, Columbia, v. 10, n. 5, p. 369-371, 1998.

MEGID,J.;DIASJUNIOR,J.G.;AGUIAR,D.M.;NARDI JUNIOR, G.; SILVA, W. B.; RIBEIRO, M. G. Tratamento da papilomatose canina com Propionibacterium acnes. Arquivo Brasileiro de Medicina Veterinária e Zootecnia, Belo Horizonte, v. 53, n. 5, p. 574-576, 2001.

MEUNIER, L. D. Squamous cell carcinoma in Beagles subsequent to canine oral papillomavirus vaccine. Laboratory Animal Science, Penicuik, v. 40, p. 568, 1990.

MILL, A. B.; CAMPBELL, K. L. Concurrent hypothyroidism, IgM deficiency, impaired T-cell mitogen response, and multufocal cutaneous squamous papillomas in a dog. Canine Practice, Santa Barbara, v. 17, n. 1, p. 15-21, 1992.

NICHOLLS, P. K.; MOORE, P. F.; ANDERSON, D. M.; MOORE, R. A.; PARRY, N. R.; GOUGH, G. W.; STANLEY, M. A. Regression of canine oral papillomas is associated with infiltration of CD4+ and CD8+ lymphocytes. Virology, New York, v. 283, n. 1, p. 31-39, 2001.

NICHOLLS, P. K.; KLAUNBERG, B. A.; MOORE, R. A.; SANTOS, E. B.; PARRY, N. R.; GOUGH, G. W.; STANLEY, M. A. Naturally ocurring, nonregressing canine oral papillomavirus infection: host immunity, vírus characterization, and experimental infection. Virology, New York, v. 265, n. 2, p. 365-374, 1999.

NICHOLLS, P. K.; STANLEY, M. A. The immunology of animal papillomaviruses. Veterinary Immunology and Immunopathology, Amsterdam, v. 73, n. 2, p. 101-127, 2000.

Canine papillomavirus. A centenary review. Journal of Comparative Pathology, Edinburgh, Inglaterra, v. 120, p. 219-233, 1999.

SHIMADA, A.; SHINYA, K.; AWAKURA, T.; NARAMA, I.; MAEDA, H.; UMEMURA, T. Cutaneous papillomatosis associated with papillomavirus infection in a dog. Journal of Comparative Pathology, Edinburgh, Inglaterra, v. 108, p. 103-107, 1993.

SUNDBERG, J. P.; SMITH, E. K.; HERRON, A. J.; JENSON, A. B.; BURK, R. D.; VAN RAST, M. Involvement of canine oral papillomavirus in generalized oral and cutaneous verrucosis in a Chinese Shar-Pei dog. Veterinary Pathology, Washington, v. 31, n. 2, p. 183187, 1994. 
SUZICH, J.A.; GHIM, S.; PALMER-HILL, F. J.; WHITE, W. I.; TAMURA, J. K.; BELL, J. A.; NEWSOME, J. A.; JENSON, A. B.; SCHLEGEL, R. Systemic immunization with papillomavirus L1 protein completely prevents the developmentof viral mucosal papillomas. Proceedings of the National Academy of Sciences of the United States of America, Washington, v. 92, n. 25, p. 11553-11557, 1995.
TIEFKE, J. P.; LOHR, C. V.; SHIRASAWA, H. Detection of canine oral papillomavirus-DNA in canine oral squamous cell carcinomas and p53 overexpressing skin papillomas of the dog using polymerase chain reaction and non-radioactive in situ hybridisation. Veterinary Microbiology, Amsterdam, v. 60, n. 2, p. 119-130, 1998.

TIZARD, I. Imunologia veterinária: uma introdução. 6.ed. Philadelphia: W. B. Saunders Company, 2000.

WALL, M.; CALVERT, C. A. Canine viral papillomatosis. In: GREENE, C. E. Infectious disease in the dog and cat. 3.ed. Philadelphia: W.B. Saunders, 2006. p. 73-78. 